\title{
THOMSON'S CAPSULAR CATARACT
}

\author{
BY :
}

\section{T. HARRISON BUTLER}

BIRMINGHAM

IN the British Journal of Ophthalmology for June, 1922 Ernest Thomson described a series of cases of opacity in the lens capsule of children. John Foster published a similar case in the same journal for August, 1924.

Thomson suggests that the incidence of this class of opacity is $1: 1,000$. This figure appears to be high. I find that during the past thirteen years I have examined at the Coventry School Clinic approximately 8,000 children. All have had the pupil dilated, all have been refracted by retinoscopy, and practically all have had a fundus examination. The condition described is so obvious that it is impossible to overlook it, and yet but two cases have come under my notice, one some years ago, and the second quite recently. My case incidence would be about 1:5,000 for I have examined many children apart from clinics.

My first case showed a brown opacity in the centre of the anterior capsule, some peripheral white opacities superficially in the lens, and some posterior synechiae. It corresponded with one type described by Thomson. I have tried to get hold of the child for slit-lamp examination but have failed.

The second case is a girl, aged 10 years. Her acuity in the right, affected, eye is $6 / 18$ with plus 2.5 sphere and plus 3.5 cylinder, axis 80 ; that of the left, normal, eye is $6 / 12$ th partly with plus 2.5 sphere and plus 2.5 cylinder axis 100 .

In the centre of the pupillary area there is a brown stippled area through which the fundus is not quite clearly seen. In the northeast periphery there are three bluish-white, cuneiform, superficial, lental opacities having the white-of-egg tone mentioned by Thomson.

The appearance seen is shown in the plate. Fig. 1 depicts the eye as seen with the slit-lamp and corneal microscope under a magnification of 9 . The brown patch resolves itself into a collection of dots which are obviously pigment granules upon the surface of the anterior capsule. Examination under a magnification of 23 and a narrow beam showed that the white opacities were entirely capsular and that the underlying cortex was perfectly transparent and normal. Under this magnification the pigment granules were seen to be stellate in form. Fig. 2 shows the appearance of the dots under a magnification of 35 . Each is a pigment star, and the poles are prolonged as grey filaments which here and there anastomose and interlace. In fact the picture is 
that of the collections of "stars" which we find so frequently upon the anterior capsule. The only difference is that the usual collection is much less extensive, in some cases consisting of two or three stars only. Probably a careful search will show them in one individual in twenty or even more frequently. These stars are vestigial remnants of the pupillary membrane. In my second case the whole character of the "stars" was typical of such an origin and there was nothing to suggest an inflammatory source. In my first case, although there were signs of past inflammation, the

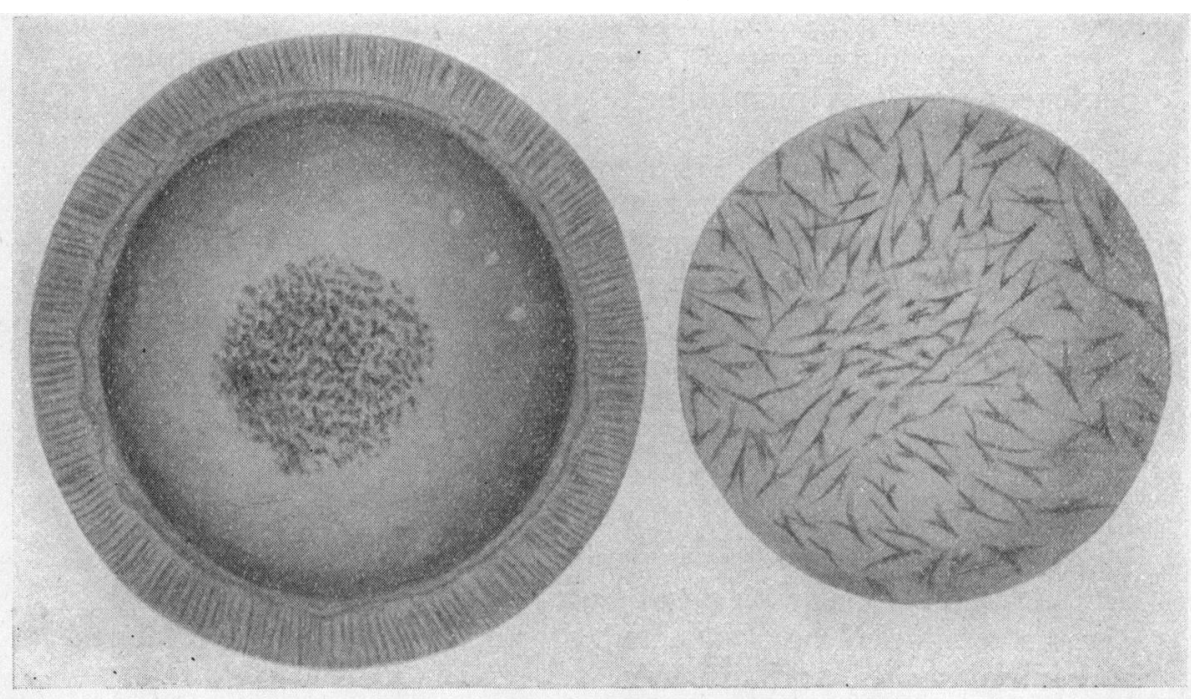

FIG. 1.

FIG. 2.

presence of a "telegraph wire" strand of the pupillary membrane in addition to the central deposit makes it certain that the anomaly is a vestigial one and not an inflammatory state.

The mere fact that the pigment granules have a stellate form is not pathognomonic of the pupillary vestige, for in time all pigment deposits upon the anterior capsule tend to the star shape, and there may be grey filamentary networks in inflammatory deposits. But the regular shape of the stars, the tendency to be tripolar, and the nature of the grey filaments, all speak for the non-inflammatory origin in the cases under notice. The white areas, wholly in the capsule, are quite unlike any inflammatory formation, and most certainly suggest a developmental abnormality.

The fact that one of my cases and several figured by Thomson show signs of past inflammation wholly supports the view that the formations seen are due to the pupillary membrane, for, as has 
been pointed out by Vogt and others, an ante-natal intrauterine inflammation of the eye, probably gonococcal, inhibits the normal retrogression of the tunica vasculosa. I have a case in which there is an anterior polar cataract with its "imprint" deeper in the lens, and a central corneal nebula. There is in this case an extensive network of vestigial pupillary membrane fibres attached to the nebula. Here an intrauterine inflammation of the cornea led to a central perforation, to an anterior polar cataract, and to incomplete absorption of the pupillary membrane. Other examples of incomplete retrogression with central capsular cataract are figured in the "Doyne Memorial Lecture" (Brit. Jl. of Ophthal., Dec., 1924, page 581, Figs. 26, 27, 28).

I have no doubt that all cases of this nature are examples of persistent pupillary membrane.

\section{A CASE OF RETROBULBAR NEURITIS FOLLOWING A SEPTIC WOUND}

BY

\section{T. HARRISON BUTLER BIRMINGHAM}

Ir is commonly supposed that retrobulbar neuritis may have a septic origin, but the focus is generally a local one associated with orbital suppuration, with nasal sinusitis, or with an apical abscess. The toxaemia may be of systemic origin, as in diabetes, influenza, abdominal sepsis, and the like.

The following case is unusual, and, as it has a medico-legal aspect, seems worthy of record :

J.H.P., male, aged 26 years, was sent to me to be examined with reference to compensation. He gave a history that five months ago he sustained a cut just above the right wrist. The wound suppurated and eventually an abscess was opened on the inner aspect of the upper arm. At this time he noted that the sight of both eyes was getting misty, and that this was especially noticeable in a strong light. The sight has slowly deteriorated and now he cannot see to read or do any form of work.

The acuity of each eye is $2 / 60$ and is not improved with glasses. There is no error of refraction. The media are clear. Each optic nerve shows well-marked temporal atrophy. The right nerve head has slightly blurred edges and small tags of white material pass from its edge to the retina. The great vessels have a film over their roots. There is still evidence of a past optic neuritis. The left nerve head is free from these signs of neuritis. 